\title{
Fertility in men with primary ciliary dyskinesia presenting with respiratory infection
}

\author{
Neil C Munro, David C Currie, Kevin S Lindsay, Timothy A Ryder, \\ Andrew Rutman, Ann Dewar, Michael A Greenstone, William F Hendry, \\ Peter J Cole
}

\begin{abstract}
Background - Primary ciliary dyskinesia is characterised by chronic rhinosinusitis, chronic bronchial sepsis (usually with bronchiectasis), dextrocardia in approximately $50 \%$ of cases, and male infertility. The latter, described in patients attending infertility clinics, results from immotile but viable spermatozoa. Experience in a respiratory clinic suggests that infertility in men is not invariable.

Methods - The seminal fluid of 12 men with primary ciliary dyskinesia, six with dextrocardia, who presented consecutively with upper and lower respiratory tract sepsis was examined. Nasal ciliary beating was dyskinetic or absent in all cases, and nasal ciliary ultrastructure was abnormal in those 11 patients examined.
\end{abstract}

Results - Viable but immotile spermatozoa with abnormal tail ultrastructure were found in the ejaculate of only two patients. Two other patients had apparently fathered children; seminology in both these cases showed a normal spermatozoa count, one with normal spermatozoal motility and normal ultrastructure, the other with moderately reduced spermatozoal motility and abnormal ultrastructure (dynein arm deficiency on the peripheral microtubule doublets). A further two patients had normal spermatozoa counts, normal spermatozoa tail ultrastructure, and normal or only moderately reduced motility of spermatozoa. The spermatozoa of one patient were normally motile but there was severe oligozoospermia, and five patients were azoospermic.

Conclusions - Not all men with primary ciliary dyskinesia have immotile spermatozoa. Seminal analysis is recommended in men with primary ciliary dyskinesia so that accurate counselling about reproductive capability may be given.

(Thorax 1994;49:684-687)

The upper and lower respiratory tracts are lined with ciliated epithelium and coordinated ciliary beating is necessary for efficient mucociliary clearance. ${ }^{1}$ The ultrastructure of respiratory tract cilia is similar to that of the tails of spermatozoa. ${ }^{2}$ Both have nine peripheral microtubule doublets and a central microtubule pair. Attached to the peripheral doublets are inner and outer dynein arms which interact with neighbouring microtubules to produce movement.

Primary ciliary dyskinesia is a congenital condition characterised by purulent rhinosinusitis, chronic bronchial sepsis which is usually associated with bronchiectasis, and, frequently, male infertility..$^{2-4}$ About $50 \%$ of patients have dextrocardia with or without situs inversus and meet the criteria for Kartagener's syndrome. The characteristic seminal analysis in primary ciliary dyskinesia is a normal number of viable but immotile spermatozoa. A common defect - usually partial or complete deficiency of one or both sets of dynein arms - may account for the dyskinetic beating of the respiratory cilia and the immotility of spermatozoan tails in this condition. ${ }^{2}$

Most men with primary ciliary dyskinesia are infertile because of immotile spermatozoa. $^{45}$ This may be because of a bias in case selection towards those attending for investigation of infertility whose respiratory symptoms were only fully investigated once immotile spermatozoa were noted. There are single case reports of men presenting with respiratory disease due to primary ciliary dyskinesia with normal seminal analysis ${ }^{6}$ and azoospermia. ${ }^{7}$ We examined the fertility of men with primary ciliary dyskinesia who presented consecutively with respiratory symptoms.

\section{Methods}

PATIENTS

All patients with persistent respiratory infection presenting to the Host Defence Unit in the Royal Brompton National Heart and Lung Hospital are investigated for the presence of bronchiectasis and underlying causes of chronic bronchial sepsis including primary ciliary dyskinesia. The clinical features of 12 men aged over 18 years who presented consecutively with respiratory symptoms and who were shown to have primary ciliary dyskinesia were recorded.

\section{DIAGNOSTIC CRITERIA}

Clinical criteria included the coexistence of persistent upper respiratory tract sepsis, chronic bronchial sepsis, and dextrocardia with or without situs inversus. ${ }^{8}$ Cytological features were reduced ciliary beat frequency, reduced ciliary motility index, and ultrastructural abnormalities on transmission electron microscopy. 
Ciliary beat frequency

Strips of nasal epithelium were obtained from the inferior nasal turbinate of each patient by brushing with a cytology brush. ${ }^{9}$ The strips of epithelium were dispersed by agitation in medium 199 (Flow Laboratories Inc, Mclean, Virginia, USA) and placed in a sealed microscope coverslip slide preparation for measurement of ciliary beat frequency. ${ }^{910}$ The epithelial cell preparation was placed on an electronically controlled warm stage (Microtech, Oxford, UK) at $37^{\circ} \mathrm{C}$ mounted on a Leitz Dialux 20 phase contrast microscope. A Leitz MPV compact microscope photometer transduced light intensity into an electrical signal. Strips of ciliated epithelium were viewed directly at a $\times 320$ magnification by bright field illumination. The cilia were positioned to interrupt the passage of light through a small diaphragm into the photometer, and the electrical signal generated was converted into a digital reading of ciliary beat frequency in hertz.

Direct viewing of the cilia allowed an assessment of their beating pattern to be made. Ciliary dyskinesia was defined as the absence of the normal coordinated pattern of ciliary movement. Ciliary immotility was defined as complete absence of ciliary beating. Measurements of ciliary beat frequency were made at 10 sites where ciliated epithelium with beating cilia (wherever possible) was seen and the mean of these readings calculated. For some patients the ciliary motility index was also determined by examining the epithelium through a graticule and was defined as the ratio of the number of squares containing motile cilia to the total number examined. ${ }^{8}$

Transmission electron microscopy of nasal cilia The ultrastructure of the nasal cilia obtained was examined by transmission electron microscopy. ${ }^{11}$ Nasal epithelium was placed in cacodylate buffered $2.5 \%$ glutaraldehyde and post fixed in $1 \%$ osmium tetroxide. After rinsing the brushings of ciliated epithelium were embedded in a drop of $2 \%$ liquid agar and gently centrifuged. The agar was allowed to solidify and then routinely processed to embedding in Araldite. Semithin $(1 \mu \mathrm{m}) \mathrm{sec}-$ tions were cut and stained with $1 \%$ toluidine blue for light microscopy, then suitable areas were selected and trimmed for ultra thin sectioning. These sections were stained with uranyl acetate and lead citrate for examination by transmission electron microscopy. Ciliary abnormalities were recorded as being either microtubular or of the dynein arms.

\section{Seminal analysis}

Examination of semen was performed using a modification of the WHO criteria. ${ }^{12}$ The number of spermatozoa per millilitre of ejaculate and their motility were recorded. Spermatozoal motility was assessed as total motility (movement of any description) and as progressive motility (rapid and linear movement). The resulting figure represents those spermatozoa with forward progression and is expressed as a percentage of the total number of spermatozoa present. The volume of the ejaculate was also noted. The presence of any naturally conceived children was taken to be evidence of fertility although paternity was not proven.

\section{Transmission electron microscopy of spermatozoa ${ }^{13}$}

After liquefaction semen was fixed for two hours in cacodylate buffered $3 \%$ glutaraldehyde, then centrifuged and resuspended in cacodylate buffer for 24 hours. The sample was post fixed in $1 \%$ osmium tetroxide, washed in $50 \%$ ethyl alcohol, then placed on a $2-4 \%$ agar plate and covered with molten agar. After solidification the sample was processed as for nasal epithelial samples.

\section{Results}

All patients had persistent rhinosinusitis and chronic bronchial sepsis, and dextrocardia was present in six of the 12 (table). Nasal cilia were completely immotile in six patients and motility was significantly reduced in the remaining six. Nasal ciliary ultrastructure was deter-

Nasal ciliary and seminal fluid characteristics of patients with primary ciliary dyskinesia

\begin{tabular}{|c|c|c|c|c|c|c|c|c|}
\hline \multirow{2}{*}{$\begin{array}{l}\text { Patient } \\
\text { no }\end{array}$} & \multirow{2}{*}{$\begin{array}{l}\text { Age } \\
(y)\end{array}$} & \multirow{2}{*}{$\begin{array}{l}\text { Cardiac } \\
\text { situs }\end{array}$} & \multirow{2}{*}{$\begin{array}{l}\text { Ciliary beat } \\
\text { frequency (hertz) }\end{array}$} & \multirow{2}{*}{$\begin{array}{l}\text { TEM of } \\
\text { nasal cilia }\end{array}$} & \multicolumn{2}{|l|}{ Seminal analysis } & \multirow{2}{*}{$\begin{array}{l}\text { TEM of } \\
\text { spermatozoa }\end{array}$} & \multirow[t]{2}{*}{ Children } \\
\hline & & & & & Spermatozoa count $\left(\times 10^{6} / \mathrm{ml}\right)$ & Motility (\%) & & \\
\hline 11 & 31 & Laevocardia & $\begin{array}{l}8 \cdot 25 \\
\text { Dyskinesia }\end{array}$ & DIA & 70 & 0 & DIOA & 0 \\
\hline 12 & 27 & Laevocardia & $\begin{array}{l}8 \cdot 2 \\
\text { Dyskinesia }\end{array}$ & DOA & 2 & 0 & DIOA & 0 \\
\hline $\begin{array}{r}10 \\
8\end{array}$ & $\begin{array}{l}28 \\
28\end{array}$ & $\begin{array}{l}\text { Dextrocardia } \\
\text { Dextrocardia }\end{array}$ & $\begin{array}{l}0 \\
4 \cdot 5 \\
95 \% \text { immotile }\end{array}$ & $\begin{array}{l}\text { DOA } \\
\text { DIA }\end{array}$ & $\begin{array}{l}30 \\
31\end{array}$ & $\begin{array}{l}50 \\
30\end{array}$ & $\begin{array}{l}\text { Normal } \\
\text { DIOA }\end{array}$ & $\begin{array}{l}2 \\
1\end{array}$ \\
\hline $\begin{array}{l}2 \\
5 \\
3 \\
1 \\
6 \\
4 \\
9 \\
7\end{array}$ & $\begin{array}{l}26 \\
38 \\
19 \\
57 \\
34 \\
33 \\
18 \\
18\end{array}$ & $\begin{array}{l}\text { Dextrocardia } \\
\text { Dextrocardia } \\
\text { Laevocardia } \\
\text { Dextrocardia } \\
\text { Laevocardia } \\
\text { Dextrocardia } \\
\text { Laevocardia } \\
\text { Laevocardia }\end{array}$ & $\begin{array}{l}95 \% \text { immotile } \\
10 \cdot 2 \\
0 \\
0 \\
0 \\
0 \\
0 \\
7.8 \\
\text { Dyskinesia } \\
11-15\end{array}$ & $\begin{array}{l}\text { DOA } \\
\text { Trans } \\
\text { DIOA } \\
\text { ND } \\
\text { DOA } \\
\text { DIOA } \\
\text { DOA } \\
\text { DIOA }\end{array}$ & $\begin{array}{l}44 \\
44 \\
<1 \\
\text { Azoospermia } \\
\text { Azoospermia } \\
\text { Azoospermia } \\
\text { Azoospermia } \\
\text { Azoospermia } \\
\\
>20\end{array}$ & $\begin{array}{l}50 \\
30 \\
50\end{array}$ & $\begin{array}{l}\text { Normal } \\
\text { Normal } \\
\text { Insuff }\end{array}$ & $\begin{array}{l}0 \\
0 \\
0 \\
0 \\
0 \\
0 \\
0 \\
0\end{array}$ \\
\hline
\end{tabular}

TEM = transmission electron microscopy; DOA = deficiency of outer dynein arms; DIA = deficiency of inner dynein arms; DIOA = deficiency of inner and outer dynein arms; trans = transposition of a peripheral doublet to replace the central microtubule pair; ND = not done; insuff $=$ insufficient for analysis. 
mined in 11 patients: 10 had deficiency of the inner or outer dynein arms, or both, and one had a transposition defect with the absent central microtubule pair being replaced by one of the peripheral doublets. In the patient in whom nasal ciliary ultrastructure was not examined the cilia were completely immotile.

Only two of the 12 patients had the reported finding of viable but immotile spermatozoa and one was oligozoospermic. The abnormality of the ultrastructure of the spermatozoa tail in both these patients was similar to that of their nasal cilia. In three patients the spermatozoa were of normal (two cases) or only moderately decreased motility, and the spermatozoa counts and ultrastructure were normal. One of these three had fathered two children, the remaining two had not attempted parenthood. In one other patient who had apparently fathered a child a normal spermatozoa count with moderately decreased motility was found. A deficiency of inner and outer dynein arms in most of the spermatozoa tails was shown by transmission electron microscopy. One patient's spermatozoa were normally motile but there was severe oligozoospermia, too few spermatozoa being present even after centrifugation for transmission electron microscopy to be performed. Azoospermia was found in five patients. Seminal analysis had been performed on one of these patients at another hospital many years previously but the results were not available. In the remaining four semen volume was normal.

There appeared to be no relation between the fertility of the patients studied and the severity of their respiratory disease, the degree of reduction of nasal ciliary beat frequency, or the ultrastructure of their respiratory cilia.

\section{Discussion}

This study represents the first and largest group of men presenting consecutively with respiratory symptoms due to primary ciliary dyskinesia in whom fertility has been examined. Sterility of three men with Kartagener's syndrome was reported in $1960^{14}$ and immotile spermatozoa were seen in one who underwent seminal analysis. The relation of infertility due to immotile spermatozoa with respiratory disease secondary to dyskinetic or immotile cilia was reported later. ${ }^{4}$

Exceptions to these findings have been reported. Five men with Kartagener's syndrome have been reported to have fathered between them 12 children. ${ }^{15} \mathrm{~A}$ further patient with Kartagener's syndrome who fathered a child had ultrastructural abnormalities of respiratory cilia but normal seminal analysis and normal spermatozoa tail ultrastructure, ${ }^{6}$ although deficiency of the inner and outer dynein arms in nasal cilia, spermatozoa tails (obtained by testicular biopsy), and epididymal cilia has been reported in the same disorder. $^{7}$

The high prevalence of azoospermia (in five of 12 patients) in primary ciliary dyskinesia has not previously been reported. None of these patients had a history of orchitis or sexually transmitted disease. All had normal secondary sexual characteristics although assay of follicular stimulating hormone levels to exclude testicular failure was not performed. Other semen characteristics such as volume and $\mathrm{pH}$ did not suggest a mechanical obstructive cause for their azoospermia. None had clinical evidence of cystic fibrosis, in which ciliary function and ultrastructure is normal but in which mesonephric testicular tissues are absent leading to infertility. Young's syndrome, ${ }^{16}$ in which sinusitis, bronchiectasis, and azoospermia are features, is associated with normal ciliary ultrastructure and absence of dextrocardia. ${ }^{817}$ At scrototomy the caput epididymis is enlarged and contains spermatozoa in a lipid rich fluid. ${ }^{18}$ While coexistence of Young's syndrome and primary ciliary dyskinesia cannot be excluded, it seems unlikely. An alternative reason for the azoospermia in five patients and the oligozoospermia in two (one with immotile spermatozoa) might be the defective transport of spermatozoa between the testis and the ejaculate. Dyskinetic or absent ciliary beating in the ciliated portion of the vas deferens might prevent normal transport of spermatozoa. If this was so, and a testicular biopsy revealed normal spermatozoa tail ultrastructure, then surgery would be indicated to bypass the functional blockage in the ciliated portion of the vas deferens.

The finding of fertility in two cases and normal seminology in a further two, whose fertility was undetermined, suggests that the defect responsible for abnormal ciliary structure may not be expressed equally in all ciliated tissues in the body. Alternatively, primary ciliary dyskinesia may represent a group of separate genetic defects presenting in a similar fashion. ${ }^{19}$ One patient has been reported with absence of inner and outer dynein arms in spermatozoa but functionally and ultrastructurally normal nasal cilia. ${ }^{20}$ This may represent dynein mosaicism as the result of a mutation of the germ cell line genes, but not affecting genes controlling somatic dynein expression. Further evidence for heterogeneity of this condition emerges from the preliminary report of a study of nasal cilia from 13 patients with immotile spermatozoa and infertility rather than respiratory infection. ${ }^{21}$ Eleven had normal ciliary beat frequency and in two patients the nasal cilia were immotile. Ultrastructural abnormalities occurred in $7-34 \%$ of the nasal cilia examined by transmission electron microscopy in 12 of the 13 cases, but were similar to the defect in the spermatozoa in only six of the cases.

All men with primary ciliary dyskinesia should be offered seminal analysis to determine numbers of spermatozoa and their motility. Only then may logical counselling on the likelihood of fertility and advice on the possibility of treatment be given to patients with this condition who may be erroneously informed that they are infertile. Similarly, parents of boys with primary ciliary dyskinesia should not be told that they will be infertile, as frequently occurs at present. They should be given a suitably guarded prognosis regarding infertility until the child's age permits seminal analysis to clarify the situation. 
Infertile patients may benefit from advanced reproductive micromanipulation techniques. These may allow non-motile or poorly motile spermatozoa to bypass the oocyte investments by subzonal insertion or direct spermatozoa injection into the oocyte. ${ }^{22}$ Spermatozoa function tests measuring zona binding ${ }^{23}$ and egg penetration ${ }^{24}$ should assist in assessing the value of such options. Perhaps of greater importance is the observed fertility of men presenting with respiratory disease due to primary ciliary dyskinesia.

N C Munro was supported by Lilly Industries, UK. This work was supported by the National Fund for the Study of Crippling Diseases (Action Research for the Crippled Child).

1 Wanner A. Clinical aspects of mucociliary transport. $A m$ Rev Respir Dis 1977;116:73-125.

2 Afzelius BA. A human syndrome caused by immotile cilia. Science 1976;193:317-9.

3 Greenstone M, Cole PJ. Primary ciliary dyskinesia. Arch Dis Child 1984;59:704-6.

4 Eliasson R, Mossberg B, Camner P, Afzelius BA. The immotile-cilia syndrome. $N$ Engl $\mathcal{F}$ Med 1977;297:1-6.

5 Mossberg B, Afzelius BA, Eliasson R, Camner P. On the pathogenesis of obstructive lung disease. Scand $f$ Respir pathogenesis of obstru
Dis 1978;59:55-65.

6 Jonsson MS, McCormick JR, Gillies CG, Gondos B. Kartagener's syndrome with motile spermatozoa. $N$ Engl $\mathcal{f}$

7 Bashi S, Khan MA, Guiris A, Johariy IA, Abid MA Immotile cilia syndrome with azoospermia. Br $¥ \mathrm{Dis}$ Ches 1988;82:194-6.

8 Greenstone M, Rutman A, Dewar A, Mackay I, Cole PJ Primary ciliary dyskinesia: cytological and clinical features. $Q \mathcal{F}$ Med 1988;67:405-30.

9 Rutland J, Cole PJ. Non-invasive sampling of nasal cilia for measurement of beat frequency and study of ultrastructure. Lancet 1980;ii:564-5.
10 Greenstone M, Logan-Sinclair R, Cole PJ. An automated method of recording ciliary beat frequency. IRCS Med Sci 1984;12:715-6.

11 Rutland J, Dewar A, Cox T, Cole PJ. Nasal brushing for the study of ciliary ultrastructure. $₹$ Clin Pathol the study of

12 WHO laboratory manual for the examination of human semen and semen cervical mucus interaction. Cambridge University Press, 1987.

13 Ryder TA, Mackenzie ML. Routine preparation of seminal fluid specimens for transmission electron microscopy. $\mathcal{F}$ Clin Pathol 1981;34:1006-9.

14 Arge E. Transposition of the viscera and sterility in men. Lancet $1960 ; \mathrm{i}: 412-4$.

15 Rott HD. Kartagener's syndrome and the syndrome of immotile cilia. Hum Genet 1979;46:249-61.

16 Young D. Surgical treatment of male infertility. 7 Reprod Fertil 1970;23:541-2.

17 Handelsman DJ, Conway AJ, Boylan LM, Turtle JR. Young's syndrome. Obstructive azoospermia and chronic sinopulmonary infections. $N$ Engl f Med 1984;310:3-9.

18 Hendry WF, Levison DA, Parkinson MC, Parslow JM, Royle MG. Testicular obstruction: clincopathological studies. Ann R Coll Surg Engl 1990;72:396-407.

19 Afzelius BA. Genetic and ultrastructural aspects of the immotile-cilia syndrome. Am $\mathfrak{f}$ Hum Genet 1981;33:852 64.

20 Walt M, Campana A, Belerna $M$, Domenighetti G Hedinger Chr, Jakob M, et al. Mosaicism of dynein in spermatozoa and cilia, and fibrous sheath aberrations in an infertile man. Andrologia 1983;15:295-300.

21 Escudier E, Escalier D, Boucherat M Bernaudin JF, Fleury J. Presence of abnormal cilia in 13 infertile men with flagellar structure abnormalities. Proc Societas Europaea Pneumologica 1988:106s.

$22 \mathrm{Ng}$ SC, Bengso A, Sathananthan H, Ratman SS. Micromanipulation: its relevance to human in vitro fertilisation. Fertil Steril 1990;53:203-19.

23 Burkman LJ, Coddington CC, Franken DR, Kruger TF, Rosenwaks Z, Hodgen GD. The hemizona assay (HZA) development of a diagnostic test for the binding of human spermatozoa to the human hemizona pellucida to predict fertilising potential. Fertil Steril 1988;49:688-97.

24 Yanagimachi $\mathrm{R}$, Yanagimachi $\mathrm{H}$, Rogers BJ. 'The use of zona free animal ova as a test system for the assessment of the fertilising capacity of human spermatozoa. Biol Reprod 1976;15:471-6. 